\title{
The role of son preference on modern contraceptive use in Bangladesh
}

\author{
Halima Akhter ${ }^{1}$, Md. Ershadul Haque ${ }^{2}$ \\ ${ }^{I}$ (Department of Business Studies, University of Information Technology \& Sciences, Bangladesh) \\ ${ }^{2}$ (Department of Statistics Biostatistics \& Informatics, University of Dhaka, Bangladesh)
}

\begin{abstract}
This study tries to examine the relationship between son preference and contraceptive use at different parities of women in Bangladesh. This study reveals that the sex composition of the surviving children moderately influences the women's practices of modern contraceptive use at lower parities. The more sons a women has, she is more likely to use modern contraceptive at parity one and two. But this is not true for the women at parity three or more. At lower parities, this behavior may be primarily because women with at least one son among their living children are less likely to want more children and they are satisfied with the sex composition of their children. Among the women at parity three or more, contraceptive using rate is lower among them who have two or more son than those women who have one living son. This variation in contraceptive use at parity three or more may owe to have at least one daughter or not satisfied with the sex composition of children or lack of consciousness about family planning.
\end{abstract}

Keyword: BDHS, modern contraceptive, parity, sex composition, son preference, trend.

\section{Introduction}

Gender preferences for children have been widely observed around the globe. The presence of a gender preference for children, particularly a preference for sons, has been found in a large number of countries, but son preference attitudes And behavior come into sight to be most widespread in an arc of countries ranging from East Asia, through South Asia, to the Middle East and North Africa. Gender preference is also manifest in developed countries such as in the U.S. and Western Europe where individuals tend to have a preference for at least one child of each sex. However, analyzing data from a cohort study in Pakistan, Hussain et al., (2000) showed that the sex of surviving children is sturdily associated with subsequent fertility and contraceptive performance. Interaction within a culture and society play an important role in shaping the attitude of people towards family and children, and just as culture varies from one region to another, so do the attitudes of the people towards the size and composition of their family. In high-fertility societies, most couples prolong to have children regardless of the number of sons and daughters they already have. In low fertility societies, the consequence of son preference is also weak because few couples want to have more than one or two children even if they do not achieve their ideal number of sons and daughters. Researchers acknowledge a tradeoff between the economic benefits of having more sons with the economic risks of having more daughters. Specifically, families with a high proportion of sons among their surviving children may feel "less demographic pressure" and therefore, freer to continue childbearing (Repetto 1972: 75), whereas families with a high proportion of daughters may cease childbearing to avoid the risks of producing an even more disadvantageous family configuration (McClelland 1979 and Park and Cho 1995). Son preference has a moderately adverse effect on contraceptive use among women at lower parities and could be a significant fence to reducing further the country's fertility rate (M. Asaduzzaman Khan and Parveen A. Khanum, 2000). Analyzing Demographic Health Survey data from 57 countries, Arnold (1997) showed that son preference remains strong in South Asian countries and, in that area, Bangladesh has the uppermost ratio of preference for sons over daughters. McNay, Arokiasamy and Cassen (2003) stayed son preference is a significant barrier to the use of the contraception among uneducated women. But the effect of the son preference on contraception reduces with an increase in women's education and household economic condition especially in the regions where son preference is strongest. Sons are generally preferred over daughters owing to a complicated interplay of economic and sociocultural factors. Once married, daughters become physically, as well as psychologically, isolated from their natal home and are hardly ever seen as making significant contributions to their natal family (Chowdhury, 1994). Sons contribute more than daughters to family income, provide adequate support in old age to their parents, compel less of a financial burden and carry forward the family name (Nag, 1991; Ali, 1989). On the other hand, the birth of a daughter is considered as bringing neither "benefit" nor "prestige" to the family. Thus, when the net efficacy of having a son outweighs that of having a daughter, parents are likely to desire sons to daughters and may be disinclined to stop childbearing awaiting their desired number of sons has been achieved. Moreover, the use of contraceptive increase with in parity, within each parity, if increased with number of sons, 
excluding for a insignificant decrease among women at parities greater than two who had only son. The main objective of this study is to examine the effect of son preference on modern contraceptive use in Bangladesh. The hypothesis of this study is that the more sons a family has, the more likely the couple is to use modern contraceptive.

\section{Materials and methods}

The data used for the completion of this study is collected from the Bangladesh Demographic and Health Survey (BDHS) conducted in 2007. The current study is based on 9322 ever married women aged 15-49 years who had at least one children and who are not currently pregnant i.e. $84.8 \%$ of total sample. Currently pregnant women are excluded from the analysis because they are not current users of contraception. It should be mentioned that BDHS data do not have information on stated preferences for children; however such a large data set provide a unique opportunity to examine whether women's fertility behavior is influenced by the sex composition of their surviving children in the family. Dependent variable of this study is current contraceptive use by method type where No method have used as reference category. Folkloric method and traditional method are merged into the same group. This study deals with a large number of control variables. In case of selecting control variables our interest is reflected on those variables, for which we eager to detect the impact on the dependent variables. Some of the variables are found to be important on socio-economic point of view while some are from demographic point of view. Socio economic variables are- Division, Type of place of residence, Respondent's education, Religion, Husband's education, Respondent's currently working, Belongs to organization, Visited by Govt. family planning workers, Heard FP massages on TV or Radio. Demographic variables are- Current age of respondents, Age 5-year group, Sex of child, Child alive. Here some of the socioeconomic variables and demographic variables are not used by their original code and these are recoded. These variables are categorized into different breakdown on the basis of socio-economic conditions and it is also bear in mind that each category contains adequate sample size. Also some of the variables are not directly obtained from BDHS 2007. Sex composition of the surviving children, expressed as the number of sons, have been used as the study variable and have been kept in the model disregarding their significance. In order to measure exposure variable initially we have used the variables "sex of child" and "child alive". These variables are considered for 20 successive births. In case of variable "sex of child" code 1 was used for Male and code 0 was used for Female. Similarly in case of variable "child alive" code 1 was used for Yes and code 0 was used for No. Then we have calculated total number of male child and total number of female child conditional that those child are alive. The "no son", which means all daughters, category have been considered as the reference for the analysis. Considering total number of children we have divided 9322 study participants into three mutually exclusive groups according to their children's sex composition namely, one child, two child, three or more child. As the total fertility rate is less than 3 (TFR $=2.7$, Mitra et al., 2007), women with three or more children are shown separately. In order to get overall idea about socio-economic and demographic characteristics of ever married women aged 15-49 years who had at least one living children and who are not currently pregnant we use percentage distribution. To investigate the pattern of contraceptive use by some selected demographic and socio-economic variables, we employed a bivariate analysis and necessary test statistics such as chi-square. If the control variable shows significant influence on dependent variable at bivariate analysis, it may cease its significant influence when other variables are controlled. Bivariate analysis only provides a preliminary idea of how important each control variable individually is by itself. Since an empirical association between two variables does not necessarily imply a causal relationship between them. The relative importance of all the variables has to be examined simultaneously by some multivariate statistical techniques. The general logistic model express a qualitative dependent variables as function of several independent variables, both qualitative and quantitative (Cox 1984). Since the dependent variable of this study has three categories so in order to find multivariate assessment multinomial logistic regression analysis was conducted to examine the adjusted effect of son preference on the practice of modern contraception after allowing for potential confounders.

\section{Trend of contraceptive use \& fertility}

The contraceptive prevalence rate for married women in Bangladesh has increased from 8 percent in 1975 to 56 percent in 2007, a sevenfold increase over more than three decades Overall, current contraceptive use has declined by two percentage points in the past three years, from 58 percent in 2004 to 56 percent in 2007, but use of modern methods has remained unchanged. Modern method using rate has increased rapidly from $5 \%$ in 1971 to $47.5 \%$ in 2007. Data from the 2007 BDHS and previous surveys show that following a nearly decadelong plateau in fertility from 1993 to 2000, fertility in Bangladesh has resumed its decline. The estimates describe the ongoing fertility transition in Bangladesh. Fertility has declined sharply, from 6.3 births per woman in 1971-75 to 2.7 births per woman in 2004-2006. 


\section{Contraceptive use at each parity and son preference}

Modern contraceptive users by number of living children and number of son were measured for ever married women age 15-49. Among them 49 percent were current user of modern contraceptive method and 9 percent were the users of others method where other method include both traditional method and folkloric method. Table 1 represents the association between contraceptive use and sex composition of the surviving children at each parity of women. Contraceptive use was significantly associated with number of surviving children (p-value < 0.05). As the number of living children increased, modern contraceptive use increased monotonically from 45 percent among those who had one surviving child to 57 percent among those who had two surviving children. But subsequently this rate declined to 47 percent among those who had three or more living children. Thus there exist curvilinear relationship between modern contraceptive use and number of living children. Investigation of the table 1 also reveals that there exist a linear relationship between sex composition of children and other contraceptive method.

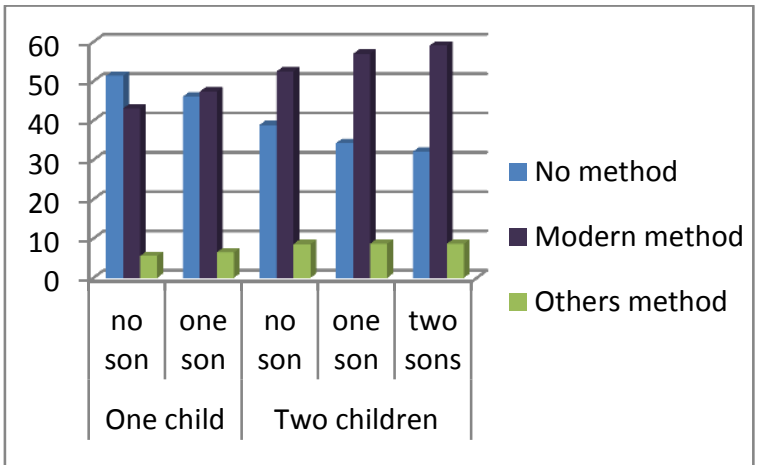

Figure 1: Association between Sex composition of children and contraceptive use by women with one child and two children.

Table 1: Percentage distribution of ever-married women aged 15-49 years using contraception, by number of children and by number of sons, Bangladesh, 2006-2007.

\begin{tabular}{|l|l|l|l|l|}
\hline $\begin{array}{l}\text { Number of children and } \\
\text { number of sons }\end{array}$ & $\begin{array}{l}\text { Modern method } \\
(\%)\end{array}$ & $\begin{array}{c}\text { Other method } \\
(\%)\end{array}$ & $\begin{array}{c}\text { No method } \\
(\%)\end{array}$ & Total (N) \\
\hline One child $^{\text {a }}$ & 45.4 & 6.0 & 48.6 & 2185 \\
No son & 43.1 & 5.6 & 51.4 & 1008 \\
One son & 47.4 & 6.5 & 46.1 & 1177 \\
Two child $^{\text {b }}$ & 56.7 & 8.7 & 34.6 & 2644 \\
No son & 52.5 & 8.6 & 38.9 & 491 \\
One son & 57.0 & 8.7 & 34.3 & 1490 \\
Two sons & 59.1 & 10.7 & 32.1 & 663 \\
Three child or more & 46.7 & 6.7 & 42.9 & 4493 \\
No son & 52.3 & 11 & 40.9 & 298 \\
One son & 48.9 & 10.6 & 40.1 & 1176 \\
Two or more sons & 46.7 & 8.9 & 44.2 & 3019 \\
\hline Overall & 49.2 & 41.9 & 9322 \\
\hline
\end{tabular}

a. P-value $<0.05 \quad$ b. $\mathrm{P}$-value $<0.10$

Among the respondents with one children $(\mathrm{N}=2185)$, who had no sons but had one living daughter were less likely to use modern contraceptive (43.1 percent) than those who had one surviving son (47.4 percent). Others method using rate was high among the women who had one living son than those women who had no son. Table 1 demonstrate that there exist significant association ( $\mathrm{p}$-value $=0.018)$ between sex composition of children and use of contraception. Modern contraceptive use increased consistently for the women who had two surviving children. Among them modern contraceptive acceptance increased from 52.5 percent for women who had no sons to 57 percent for women with one living sons to 59 percent for women with two surviving sons. Table 1 shows that for women with two children, modern contraceptive use had significant association with sex composition of surviving children ( $\mathrm{p}$-value $=0.059$ ). A slight reversal in trends was observed among the women who had three or more living children (Table 1). Among women with three or more children, who had no surviving son were more likely to use modern contraceptive method (52.3 percent) than those women with one living son (48.9 percent) and women with two or more living sons ( 46.7 percent). There was no substantiation of association between modern contraceptive use and the number of sons among women with three or more children ( $\mathrm{p}$-value $=0.294)$. 
Bivariate analysis was also conducted in order to identify which variables have significant association with contraceptive use for three groups of women separately (table 2). For each group it has been found that most of the variables have significant association with contraceptive use.

Table 2: Percentage distribution of contraceptive using behavior of women age 15-49 years by some selected characteristics for different numbers of children, Bangladesh 2006-2007.

\begin{tabular}{|c|c|c|c|}
\hline \multirow[t]{2}{*}{ Variables } & \multicolumn{3}{|c|}{ Number of children } \\
\hline & One & Two & Three \\
\hline Age(Years) & & & \\
\hline$<24$ & $52.0^{\mathrm{c}}$ & 60.5 & $50.8^{\mathrm{d}}$ \\
\hline $25-34$ & 40.2 & 63.5 & 58.6 \\
\hline $35+$ & 19.7 & 41.7 & 39.6 \\
\hline Division & & & \\
\hline Barisal & $50.4^{\mathrm{b}}$ & 57.2 & 48.0 \\
\hline Chittagong & 38.9 & 49.5 & 40.8 \\
\hline Dhaka & 45.2 & 59.0 & 50.4 \\
\hline Khulna & 51.1 & 60.0 & 52.8 \\
\hline Rajshahi & 56.8 & 65.1 & 58.5 \\
\hline Sylhet & 18.8 & 36.7 & 30.9 \\
\hline Type of place of residence & & & \\
\hline Urban & $49.4^{\mathrm{d}}$ & $60.5^{\mathrm{c}}$ & $50.8^{\mathrm{c}}$ \\
\hline Rural & 42.7 & 54.0 & 44.5 \\
\hline Respondent's education & & & \\
\hline No education & $27.8^{\mathrm{c}}$ & $51.1^{\mathrm{c}}$ & $43.0^{\mathrm{c}}$ \\
\hline Primary & 39.9 & 55.5 & 50.2 \\
\hline Secondary & 53.1 & 60.0 & 47.4 \\
\hline Higher & 52.8 & 65.0 & 62.0 \\
\hline Religion & & & \\
\hline Islam & $44.7^{\mathrm{a}}$ & $56.6^{\mathrm{d}}$ & $46.0^{\mathrm{d}}$ \\
\hline Others & 51.0 & 57.8 & 54.3 \\
\hline Husband's education & & & \\
\hline No education & $35.7^{\mathrm{c}}$ & $53.2^{\mathrm{c}}$ & $45.2^{\mathrm{c}}$ \\
\hline Primary & 46.0 & 56.7 & 47.5 \\
\hline Secondary & 49.2 & 59.1 & 48.0 \\
\hline Higher & 50.2 & 59.6 & 7.6 \\
\hline Respondents working & & & \\
\hline No & 45.6 & $54.6^{\mathrm{a}}$ & $44.5^{\mathrm{c}}$ \\
\hline Yes & 44.9 & 60.9 & 51.6 \\
\hline Belongs to organization & & & \\
\hline No & $42.3^{\mathrm{c}}$ & $52.7^{\mathrm{c}}$ & $41.7^{\mathrm{c}}$ \\
\hline Yes & 52.1 & 63.1 & 53.6 \\
\hline Visited by Family Planning workers & & & \\
\hline No & $42.5^{\mathrm{c}}$ & $52.5^{\mathrm{c}}$ & $42.8^{\mathrm{c}}$ \\
\hline Yes & 64.1 & 78.1 & 69.7 \\
\hline Heard FP massage on TV or Radio & & & \\
\hline No & $39.6^{\mathrm{c}}$ & $52.5^{\mathrm{c}}$ & 43.7 \\
\hline Yes & 52.4 & 62.7 & 53.7 \\
\hline
\end{tabular}

a . p-value $<0.05 \quad$ b. p-value $<0.10 \quad$ c . p-value $<0.001 \quad$ d. p-value $<0.01$

\section{Multivariate analysis}

Multivariate logistic regression analysis were conducted to assess the net effect of son preference on the use of contraception of ever married and non-pregnant women after allowing for potential confounders and to understand the importance of explanatory variable, when taken together, explaining the variation in modern contraceptive use at each parity of women. Among the variables initially considered, respondent's education was found to be highly correlated with her husband's education. Therefore, in order to avoid the problem of multicollinearity, a decision was made to drop the respondent's education from the analysis.

At first, three sets of potential confounder for three different logistic model were identified by considering their independent potential contribution to the current use of contraception by using chi-square test. Subsequently, three logistic regression models were fitted for different number of children such as one children, two children, three or more children, by considering the current contraceptive use by method type as the outcome variable, where "no method" category was considered as the reference category. In case of study variable, sex composition of the surviving children expressed as the number of son, "no son" category which means all daughters was considered as the reference category. The results of the multivariate analyses are in broad agreement with the bivariate analyses. For the model, women with one child (table 3), sex composition of the surviving children is found to be significantly associated ( $p$-value $<0.01$ ) with the current use of modern contraception after adjusting for the confounding factor. But for others contraceptive methods there exists insignificant association. 
Table 3: Multivariate assessment of association between sex composition of surviving children and use of contraceptive among ever married women who had one child.

\begin{tabular}{|c|c|c|}
\hline \multirow[t]{2}{*}{ Variables } & \multicolumn{2}{|c|}{ Adjusted-OR $^{\mathrm{a}}$} \\
\hline & Modern method vs No method & Others method vs No method \\
\hline Number of sons & & \\
\hline No son & $1.0^{\mathrm{b}}$ & $1.0^{\mathrm{b}}$ \\
\hline One son & $1.29^{\mathrm{c}}$ & 1.27 \\
\hline Age group (years) & & \\
\hline$<24$ & $1.0^{\mathrm{b}}$ & $1.0^{\mathrm{b}}$ \\
\hline $25-34$ & $0.55^{\mathrm{d}}$ & 1.02 \\
\hline $35+$ & $0.22^{\mathrm{d}}$ & $0.55^{\mathrm{e}}$ \\
\hline Type of residence & & \\
\hline Urban & $1.0^{\mathrm{b}}$ & $1.0^{\mathrm{b}}$ \\
\hline Rural & $0.76^{\mathrm{c}}$ & 0.96 \\
\hline Religion & & \\
\hline Islam & $1.0^{\mathrm{b}}$ & $1.0^{\mathrm{b}}$ \\
\hline Others & $1.30^{\mathrm{e}}$ & 1.42 \\
\hline Husband's education & & \\
\hline No education & $1.0^{\mathrm{b}}$ & $1.0^{\mathrm{b}}$ \\
\hline Primary & $1.26^{\mathrm{e}}$ & 1.01 \\
\hline Secondary & $1.33^{\mathrm{f}}$ & 1.26 \\
\hline Higher & $1.92^{\mathrm{d}}$ & $2.32^{\mathrm{c}}$ \\
\hline Belongs to organization & & \\
\hline No & $1.0^{\mathrm{b}}$ & $1.0^{\mathrm{b}}$ \\
\hline Yes & $1.6^{\mathrm{d}}$ & $1.51^{\mathrm{f}}$ \\
\hline $\begin{array}{l}\text { Visited by family planning } \\
\text { workers }\end{array}$ & $10^{\mathrm{b}}$ & $10^{\mathrm{b}}$ \\
\hline No & $2.31^{\mathrm{d}}$ & $1.65^{\mathrm{e}}$ \\
\hline Yes & & \\
\hline Heard FP massage on TV or & $1.0^{\mathrm{b}}$ & $1.0^{\mathrm{b}}$ \\
\hline Radio & $1.43^{\mathrm{d}}$ & $1.41^{\mathrm{e}}$ \\
\hline No & & \\
\hline Yes & & \\
\hline
\end{tabular}

a . adjusted odds ratio after adjustment for potential confounders

b. reference category c . p-value $<0.01$

d. p-value $<0.001$

e. p-value $<0.10$

f. p-value $<0.05$

Women with one son were 1.3 times likely to be practicing modern contraceptive compared with women having only one daughter. Age of women appears to have highly significant (p-value < 0.001 ) association with use of modern contraceptive (table 3) .Respondents in the age group 25-34 were 0.55 times likely to use modern contraceptive than the respondents in the age group $<24$. Rural women were 0.76 times likely to use modern contraceptive than the urban women. There exist significant association between use of modern contraceptive method and type of residence. Women whose husband's had higher education were 1.9 times likely to use modern contraceptive than women whose husband's had no education. Women whose husband's had higher education were 2.32 times likely to use others contraceptive than women whose husband's had no education. Among the women who were the member of any organization, were 1.7 times likely to use modern contraceptive than the women who were not member, which is highly significant. There exist highly significant association in case of belongs to organization, visited by government's family planning workers, heard family planning massage on TV or Radio. Women who were visited by government's family planning workers during the period six months prior to the interview are 2.3 times likely to use modern contraceptive and 1.7 times likely to use others contraceptive method than those women who were not visited. Similarly, (table 3)women who heard family planning massage on TV or Radio were 1.4 times likely to use modern contraceptive and others contraceptive method than those who were not heard any massage.

Table 4: Multivariate assessment of association between sex composition of surviving children and use of contraceptive among ever married women who had two children.

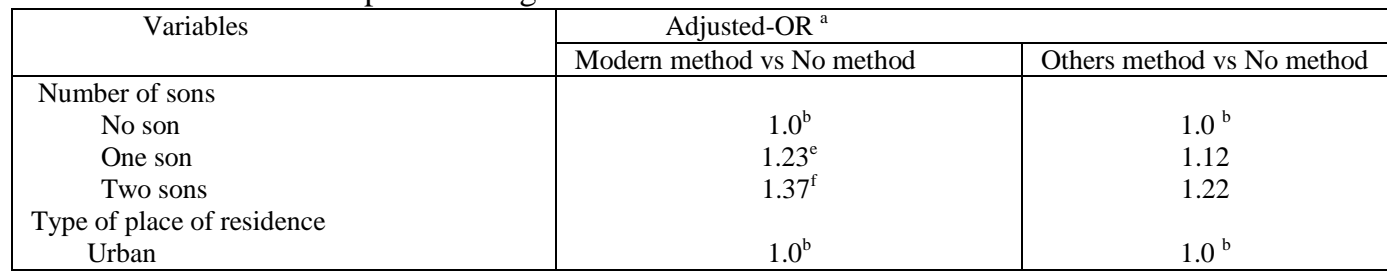




\begin{tabular}{|l|c|c|}
\hline Rural & $0.70^{\mathrm{d}}$ & $0.72^{\mathrm{f}}$ \\
Religion & & $1.0^{\mathrm{b}}$ \\
Islam & $1.0^{\mathrm{b}}$ & $2.12^{\mathrm{d}}$ \\
Others & 1.25 & $1.0^{\mathrm{b}}$ \\
Husband's education & $1.0^{\mathrm{b}}$ & 1.19 \\
$\quad$ No education & 1.14 & 1.18 \\
Primary & $1.24^{\mathrm{e}}$ & $3.14^{\mathrm{d}}$ \\
Secondary & $1.66^{\mathrm{c}}$ & $1.0^{\mathrm{b}}$ \\
Higher & $1.0^{\mathrm{b}}$ & 1.25 \\
Respondent currently working & $1.30^{\mathrm{c}}$ & $1.0^{\mathrm{b}}$ \\
No & $1.0^{\mathrm{b}}$ & $1.36^{\mathrm{e}}$ \\
Yes & $1.55^{\mathrm{d}}$ & $1.0^{\mathrm{b}}$ \\
Belongs to organization & $1.0^{\mathrm{b}}$ & 2.17 \\
No & $3.97^{\mathrm{d}}$ & $1.0^{\mathrm{b}}$ \\
Yes & $1.0^{\mathrm{b}}$ & $1.48^{\mathrm{f}}$ \\
\hline Heard FP massage on TV or Radio & $1.49^{\mathrm{d}}$ & \\
No & & \\
Yes & & \\
Visited by FP workers & & \\
Yes & & \\
\hline
\end{tabular}

a . Adjusted odds ratio after adjustment for potential confounders

b. Reference category, c. p-value $<0.01$, d . p-value $<0.001$,e . p-value $<0.10$, f . p-value $<0.05$

For this model, women with two children, sex composition of the surviving children is found to be significantly associated with the current use of modern contraception after adjusting for the confounding factor where $\mathrm{p}$-value $<0.10$ for women who had one son and one daughter and $\mathrm{p}$-value $<0.05$ for the women who had two sons and no daughter. Women with one son were 1.2 times (table 4) likely to be practicing modern contraceptive compared with women having two daughters. Women with two sons were 1.4 times likely to be practicing modern contraceptive compared with women having only two daughters. There exists insignificant association in case of other contraceptive methods. Residence of respondents was highly significant with modern contraceptive use. Rural women were less likely to use contraceptive than the urban women. Women whose husband's had higher education are 1.7 times likely to use modern contraceptive than women whose husband's had no education. There exist significant association between husband's education and modern contraceptive use except women whose husband had primary education. Women whose husband was higher educated were 3.1 times likely to use others contraceptive methods compared to the women whose husband had no education. Among the women who were the member of any organization, were 1.3 times likely to use modern contraceptive than the women who were not member, which is highly significant. There exist highly significant association ( $\mathrm{p}$-value $<0.001$ ) in case of belongs to organization, visited by government's family planning workers, heard family planning massage on TV or Radio. Women who were visited by government's family planning workers during the period six months prior to the interview were 1.5 times likely to use modern and others contraceptive than those women who were not visited. Similarly, women who heard family planning massage on TV or Radio during the period one month prior to the interview were 4 times likely (table 4) to use modern contraceptive than those who were not heard any massage.

Table 5: Multivariate assessment of association between sex composition of surviving children and use of contraceptive among ever married women who had three or more children.

\begin{tabular}{|l|c|c|}
\hline \multirow{2}{*}{ Variables } & \multicolumn{2}{|c|}{ Adjusted-OR $^{\mathrm{a}}$} \\
\cline { 2 - 3 } & Modern method vs No method & $\begin{array}{l}\text { Others method vs No } \\
\text { method }\end{array}$ \\
\hline Number of sons & $1.0^{\mathrm{b}}$ & $1.0^{\mathrm{b}}$ \\
$\quad$ No son & 1.06 & $1.64^{\mathrm{e}}$ \\
One son & 1.01 & $1.52^{\mathrm{e}}$ \\
Two or more sons & $1.0^{\mathrm{b}}$ & $1.0^{\mathrm{b}}$ \\
Age group (years) & 1.24 & 1.18 \\
$\quad<24$ & $0.61^{\mathrm{c}}$ & 1.40 \\
$25-34$ & $1.0^{\mathrm{b}}$ & $1.0^{\mathrm{b}}$ \\
35+ & $0.70^{\mathrm{d}}$ & $0.77^{\mathrm{f}}$ \\
Type of residence & $1.0^{\mathrm{b}}$ & $1.0^{\mathrm{b}}$ \\
Urban & $1.45^{\mathrm{c}}$ & 1.29 \\
Rural & & $1.0^{\mathrm{b}}$ \\
Religion & $1.0^{\mathrm{b}}$ & 1.03 \\
Islam & 1.07 & \\
Others & & \\
Husband's education & No education & \\
Primary & & \\
\hline
\end{tabular}


The role of son preference on modern contraceptive use in Bangladesh

\begin{tabular}{|c|c|c|}
\hline $\begin{array}{l}\text { Secondary } \\
\text { Higher }\end{array}$ & $1.22^{\mathrm{f}}$ & $1.56^{\mathrm{c}}$ \\
\hline $\begin{array}{l}\text { Higher } \\
\text { Respondent currently working }\end{array}$ & & \\
\hline No & $1.0^{\mathrm{b}}$ & $1.0^{\mathrm{b}}$ \\
\hline Yes & $1.38^{\mathrm{d}}$ & $1.39^{\mathrm{c}}$ \\
\hline Belongs to organization & & \\
\hline No & $1.0^{\mathrm{b}}$ & $1.0^{\mathrm{b}}$ \\
\hline Yes & $1.57^{\mathrm{d}}$ & $1.21^{\mathrm{e}}$ \\
\hline Heard FP massage on TV/ Radio & & \\
\hline No & $1.0^{\mathrm{b}}$ & $1.0^{\mathrm{b}}$ \\
\hline Yes & $1.42^{\mathrm{d}}$ & 1.21 \\
\hline Visited by FP workers & & \\
\hline No & $1.0^{\mathrm{b}}$ & $1.0^{\mathrm{b}}$ \\
\hline Yes & $3.64^{\mathrm{d}}$ & $2.71^{\mathrm{d}}$ \\
\hline
\end{tabular}

a . adjusted odds ratio after adjustment for potential confounders, $\mathrm{b}$. reference category, c . p-value $<0.01$, d. p-value $<0.001$, e . p-value $<0.10, \mathrm{f}$. p-value $<0.05$

For this model, women with three or more children(table 5), sex composition of the surviving children is found to be insignificantly associated with the current use of modern contraception after adjusting for the confounding factor among the women who had either no son or one son or two or more sons. Women with one son are 1.6 times likely to be practicing others contraceptive compared with women having no son. Women with two or more son are 1.5 times likely to be practicing others contraceptive compared with women having no son. There exists significant association in case of other contraceptive methods. Women who had one son were 1.6 times likely to use other contraceptive method than those women who had no son. Similarly women who had two or more sons are 1.5 times likely to use others contraceptive than those women who had no son. Thus, Women with higher parity i.e. who had three or more children were more using others methods than modern method as they were not conscious about family planning. Age group 35+ of women appears to have highly significant (p-value $<0.01$ ) association with the use of modern contraceptive. Residence of respondents was highly significant with contraceptive use. Rural women were less likely to use contraceptive than the urban women. Non-Muslim women were 1.5 times likely to use modern contraceptive than the Muslim women. Religions of respondents have significant association with modern contraceptive use and insignificant association with others method. Women whose husband's had higher education were 1.4 times likely to use modern contraceptive than women whose husband's had no education. There exist significant association between husband's education and contraceptive use except women whose husband had primary education. Women whose husband had higher education were 1.9 times likely to use others contraceptive methods compared to the women whose husband had no education. Women who were currently working were 1.4 times likely to use contraceptive compared to the women who were not working. Among the women who were the member of any organization, were 1.6 times likely to use modern contraceptive than the women who were not member, which is highly significant $\mathrm{p}$-value $<0.001$. Women, who were the member of any organization, were 1.2 times likely to use others method compared to the women who were not the member of any organization. Among the respondent who heard family planning massage on TV or Radio were 1.4 times likely to use modern contraceptive than the women who don't hared such information. Women who were visited by government's family planning workers during the period six months prior to the interview were 3.6 times likely to use modern contraceptive and 2.7 times likely to use others contraceptive method than those women who were not visited and there exist highly significant (p-value $<0.001)$ association.

\section{Summary and conclusion}

The aim of the study is to examine the effect of son preference on modern contraceptive use. The study utilizes the data from 2007 Bangladesh Demographic and Health Survey (BDHS). This study shows that the contraceptive prevalence rate for married women in Bangladesh has increased from 8 percent in 1975 to 56 percent in 2007, with 48 percent using a modern method and 8 percent rely on traditional method. Overall, current contraceptive use has declined by two percentage points in the past three years, from 58 percent in 2004 to 56 percent in 2007, but use of modern methods has remained unchanged. Fertility has declined sharply, from 6.3 births per woman in 1971-75 to 2.7 births per woman in 2004-2006. From this study, we can see that there exist a strong association between sex composition and practice \& types of contraception. At parity one, among the women who had one son most of them (47.4 percent) are using modern contraceptive method and only few of them (6.5 percent) are using others method (traditional and folkloric) while 46.1 percent don't using any contraceptive method. Among them who had no surviving son but had only one daughter, most of them (51.4 percent) are not using any method, 43.1 percent of them are using modern method and few of them (5.6 percent) are using others method. There exist significant association ( $\mathrm{p}$-value $<0.05)$ between sex composition of children and contraceptive use at parity one of women (from Table 1). At parity two, among the women who had two living sons most of them (59.1 percent) are using modern contraceptive method and among the women 
who had one son 57 percent are using modern method. At parity two of women, others contraceptive method using rate is approximately same whether she had no son or one son or two sons. There exist significant association (p-value < 0.10 ) between sex composition of child \& contraceptive use at parity two (from Table 1). At parity three or more, modern contraceptive using rate is high (52.3 percent) among the women who had no surviving son low (46.7 percent) among the women who had two or more sons. Others method using rate is high among the women who had one son (11 percent) and who had two or more son (10.6 percent). There exists insignificant association between sex composition and contraceptive use among women at parity three or more. This study reveals that the sex composition of the surviving children moderately influences the women's practices and types of contraceptive use at lower parities. The women who have more sons are more likely to use contraceptive at parity one and two. But this is not true for the women at parity three or more. For three or more children, who had more son are more likely to use traditional and folkloric method. At lower parities, this behavior may be primarily because women with at least one son among their living children are less likely to want more children and they are satisfied with the sex composition of their children. Among the women at parity three or more, contraceptive using rate is lower among them who have two or more son than those women who have one living son. This variation in contraceptive use at parity three or more may owe to have at least one daughter or not satisfied with the sex composition of children or lack of consciousness about family planning. This study also exposes that some socio-economic and demographic factors also affecting the women's contraceptive using behavior. Women's in the age group 25-34 are more using contraceptive at parity one and three or more. Contraceptive prevalence rate is lower in the Sylhet division at each parity of women. Rural women are more likely to have son preference as compared to urban women at each parity. Religious belief plays a vital role in determining attitudes towards the sex of the children and hence influencing the use of contraceptive. The odds of Muslim women are less likely to use contraceptive than the non-Muslim women at each parity. The women whose husband have higher education are more likely to use contraceptive as compared to the women whose husband have no education at each parity of women and among them others method using rate is high at parity two. The women, who were currently working at the time of the study, are more likely to use contraceptive as compared to the women who were not working at parity two and three or more. At each parity of women, belonging to any organization are more likely to use contraceptive as compared to other women. Women who were visited by government family planning workers or who heard family planning massage on electronic media such as TV or Radio are more likely to use contraceptive than their counterparts. For a better understanding of son preference, it is important to bear in mind the socio-economic and cultural settings of the country. In a society such as in Bangladesh, where men are the traditional authorities in their families, women often cannot make decisions themselves regarding family size and contraceptive use, although they carry a heavy burden of poor health related to reproduction. Women's contributions are often unrecognized in the family as well as by society; however, their worth is predicated mainly on their ability to produce children, particularly sons. The social and cultural milieu does not allow women to work outside the home, especially in rural areas. Women who go outside the home for work are often considered to be of low social status (Piet-Pelon et al., 1999).The norm of marginalizing women teaches them to accept dependence and deprivation relative to the male members of their family (Schuler and Hashemi, 1994).

The key finding of this study is that son preference has unfavorable consequence on modern contraceptive use among ever married women at lower parities in Bangladesh.

\section{References}

[1]. Hussain, R., F.F. Fikree and H.W. Berendes (2000). "The role of son preference in reprodudive behavior in Pakistan" Bulletin of the World Health Organization 78(3):379-388.

[2]. Repetto, R.G. (1972). "Son preference and fertility behavior in developing countries" Studies in Family Planning 3:70-76.

[3]. McClelland, Gary H. 1979. "Determining the impact of sex preferences on fertility: A consideration of parity progression ratio, dominance, and stopping rule measures." Demography 16(3): 377- 388.

[4]. Park, Chai B. and Nam-Hoon Cho. 1995. "Consequence of son preference in a low-fertility society: Imbalance of the sex ratio at birth in Korea ".Population and Development Review 21(1): 59-84.

[5]. M. Asaduzzaman Khan and Parveen A. Khanum, (2000). "Influence of son preference on contraceptive use in Bangladesh" AsiaPacific Population Journal.

[6]. Arnold, F. (1997) "Gender preference in children" DHS Comparative Studies No. 23 (Calverton, Maryland, Macro International, Inc.).

[7]. McNay, Kirsty, Perianayagam Arokiasamy, and RobertH. Cassen. 2003. "Why are uneducated women in India using contraception? A multilevel analysis." Population Studies 57:21-40.

[8]. Chowdhury, M.K. (1994). "Mother's education and effect of son preference on fertility in Matlab, Bangladesh" Population Research and Policy Review 13:257-273.

[9]. Nag, M. (1991). "Sex preference in Bangladesh, India and Pakistan and its effect on fertility" Demography India 20:163-185.

[10]. Ali, S.M. (1989). "Does son preference matter?" Journal of Biosocial Science 21(4):399-408.

[11]. Bangladesh Demographic and Health Survey, 2007. Dhaka Bangladesh nad Calverton, Maryland, USA: National Institute of Population Research and Training (NIPORT), Mitra and Associates, and Macro International.2009.

[12]. Cox, D. R. and Oakes, D. 1984. Analysis of survival data, London: Chapman and Hall, pp. 4-5.

[13]. Piet-Pelon, N.J., U. Rob and M.E. Khan (1999). Men in Bangladesh, India and Pakistan: Reproductive Health Issues (Dhaka,Bangladesh, Karshaf Publishers).

[14]. Schuler, S.R. and S.M. Hashemi (1994). "Credit programs, women's empowerment, and contraceptive use in rural Bangladesh" Studies in Family Planning 25(2):65-76. 